Cure is possible in small cell lung cancer, albeit in only a small proportion of patients mostly within a good prognosis category. This, and the chemosensitivity of the tumour imply that an unknown proportion of other patients in whom a complete response is obtained are nearly cured. Priority should, therefore, be given to exploring methods of increasing the intensity of chemotherapy.

Consultant Physician,

STEPHEN G SPIRO

Royal Brompton and National Heart Hospital,

London SW3 6HP

1 Mountain CF, Carr DT, Anderson WAD. A system for the clinical staging of lung cancer. Semin Oncol 1974:120:130-8.

2 Piehler JM, Pairolero PC, Weiland LH, Offord KP, Payne WS, Bernatz PE. Bronchogenic carcinoma with chest wall invasion. Ann Thorac Surg 1982;34:684-91.

3 Nakahashi $\mathrm{H}$, Yasumoto $\mathrm{K}$, Ishida $\mathrm{T}$, et al. Results of surgical treatment of patients with $\mathrm{T}_{3}$ nonsmall cell lung cancer. Ann Thorac Surg 1988;46:176-81

4 Mountain CF. A new international staging system for lung cancer. Chest 1986;89(suppl):22-33.

5 Naruke T, Goya T, Tsuchiya R, Suemasu K. The importance of surgery to non-small cell carcinoma of lung with mediastinal lymph node metastasis. Ann Thorac Surg 1988;46:609-10.
6 Pearson FG, DeLarue NC, Ilves R, Todd TRJ, Cooper JD. Significance of positive superior mediastinal nodes identified in mediastioscopy in patients with resectable cancer of the lung. f Thorac Cardiovasc Surg 1982;83:1-11.

Van Houtte P, Rocmans $\mathrm{P}$, Smets $\mathrm{P}$, et al. Postoperative radiation therapy in lung cancer: controlled trial after resection of curative design. Int f Radiat Oncol Biol Phys 1980;6:983-6.

8 Lung Cancer Study Group. Effects of postoperative mediastinal radiation on completely resected stage II and stage III epidermoid cancer of the lung. $N$ Engl F Med 1986;315:1377-81.

9 Lee RE. Radiotherapy of bronchogenic carcinoma. Semin Oncol 1974;1:245-52.

10 Coy P, Kennelly GM. The role of curative radiotherapy in the treatment of lung cancer. Cancer 1980;45:698-702.

11 Edinburgh Lung Cancer Group. Patients presenting with lung cancer in south east Scotland. Thorax 1987;42:853-7.

12 Price P, Hoskin PJ, Easton D, Austin D, Palmer SG, Yarnold JR. Prospective randomised trial of single and multifraction radiotherapy schedules in the treatment of painful bony metastases. Radiother Oncol 1986;6:247-55.

13 Souhami L, Law K. Longevity in small cell lung cancer. Br 7 Cancer 1990;61:548-9.

14 Souhami L, Bradbury I, Geddes DM, Spiro SG, Harper PG, Tobias JS. Prognostic significance of laboratory parameters measured in diagnosis in small cell lung cancer. Cancer Res 1985;45: laboratory

15 Rawson NSB, Peto J. An overview of prognosis factors in small cell lung cancer. A report from the subcommittee for the management of lung cancer of the United Kingdom coordinating committee on cancer research. Br f Cancer 1990;61:597-604.

16 Medical Research Council Cancer Working Party. Controlled trial of twelve versus six courses of chemotherapy in the treatment of small cell lung cancer. Brf Cancer 1989;59:584-90.

17 Splinter TAW. Induction plus maintenance chemotherapy (CT) in small cell lung cancer (SCLC). Definitive evaluation. Lung Cancer 1988;4:A100.

\title{
General practice fundholding
}

\section{The benefits and risks have not been carefully weighed}

Most worthwhile interventions in medicine carry risks. In deciding whether or not an intervention is worth while the doctor balances the risks against the benefits. Logically, a similar balancing of risks and benefits should be applied to managerial or policy changes in the NHS, such as the voluntary scheme whereby large general practices can opt to manage the funds that pay for their patients' elective procedures, drugs and appliances, paramedical services, outpatient appointments, and investigations. Most of the discussion surrounding the scheme, however, emphasised either the benefits or the risks, and not their balance. Worse still, there are no data from controlled experiments to assess the balance, as is usually the case for new medical interventions. ${ }^{12}$ Another issue is to whom benefits and risks might accrue. Much of the debate has centred on the consequences for the general practitioner, but those affected include the patient; the district health authority in which the general practitioner practises; local providers, including NHS trusts; the family health services authority; and the community at large.

The main benefits for the patient stem from the wider range of choice offered to the fundholding general practitioner. In an ideal world a knowledgeable patient could review the care options with his or her general practitioner and decide on the optimum plan. Evidence on consumer choice in health care comes mainly from the United States, where it has been found that "consumers understand clearly that there are trade offs among choices and have no difficulty in articulating their preferences." ${ }^{3}$ The key to securing these benefits, however, is knowledge about the available options by either the patient or the general practitioner. This will require a greater commitment than in the past to producing relevant information, although how much difference this will make is unclear. One American study found that the availability of statistics on hospital mortality had only limited impact on patients' choices, more influential was the preference of doctors, tradition, convenience, and word of mouth. ${ }^{+}$The other main benefits to patients are likely to come from improvements in services delivered by the practices themselves and the greater access to hospital services that fundholding practices may negotiate. There are already signs that hospital providers plan to offer improved reporting after hospital based investigations, special deals for drugs, and free bus services.
The main risk to patients is that the fund, once agreed, will not be sufficiently generous and that care will have to be rationed. Since the funds are likely to be set as a high level, at least initially, this risk is minor. A greater long term risk is that fundholding may harm the doctor-patient relationship if patients become sensitised to the potential conflicts doctors face in weighing up options for care when some of the options demand expenditure from the fund. Evidence from the United States suggests that these conflicts exist in health maintenance organisations, ${ }^{56}$ but the impact on the doctorpatient relationship and on the quality of care is uncertain.

The benefits and risks to the general practitioner largely mirror those to the patient. Fundholding will enable practitioners more easily to maintain freedom of referral, and any savings can be used to improve the range and quality of services provided by the practice. Such improvements are already being made with the grants made for information systems in practices contemplating fundholding. There is, of course, the possibility of financial embarrassment if, because of an unexpected demand for services or a major change in treatment technology, the budget is stretched. With a list of 11000 , large year to year variations in need could easily occur. Probably the greatest risk for practitioners is that they will be placed in the unenviable role of rationers of care. Currently general practitioners refer to the hospital and have little influence over, or accountability for, waiting times. If they hold the funds patients may also hold them responsible for waiting lists.

Although patients and general practitioners are most affected by fundholding, others have an interest. The purchasing authority (often the district health authority) could benefit if fundholding prompts general practitioners to scrutinise more closely the care received by their patients. This benefit may, however, be far outweighed by the risk that health care priorities will be changed. The general practice's funds will be directly transferred from the authority's budget so it will have less scope to determine the level of resources to be devoted to particular health care needs. The tacit view of the act is that the long waiting times for certain elective procedures are the result of inefficiency. What if those waiting times reflect a higher priority, appropriately given, to other care groups in the light of budgetary constraints? 
Health care providers, be they directly managed units, self governing trusts, or private hospitals, will also be affected by fundholding. The main benefit to them is that they can secure more business by targeting fundholding practices. On the other hand, they may decide to concentrate on meeting the needs of the main purchasing authorities. The new family health services authorities may also think that the interest in the fundholding general practitioner gives them an opportunity to have a wider influence in the provision of health care. On the other hand, much of their time and effort will be directed towards those practices that are not fundholding.

The final party in the assessment of the benefits and risks of fundholding is the community at large. Perhaps only $10 \%$ of the population will initially be registered with fundholding practices. If greater consumer awareness on the part of general practitioners and their patients has an appreciable impact the biggest potential benefit of fundholding is that it will improve the quality of primary and secondary care for all the population. The biggest risk is that fundholding will increase the inequalities in health care provision if some practices can deliver a better standard of service than others. This is particularly so since the minimum practice size for fundholding excludes the many singlehanded and small practices that are more common in inner city areas.

As there have been few opportunities to assess the benefits and risks of fundholding before its implementation, it will be important to monitor both efficacy and "adverse reactions" after its implementation. Some research is planned ${ }^{7}$ and more is needed. Everyone, including the government, should realise that the inappropriate application of managerial innovations can do as much, if not more, harm to patients as an untested drug, device, or surgical procedure.

Professor of Economics,

MICHAEL DRUMMOND

Centre of Economics,

University of York,

York YO1 5DD

Acting Director of Public Health,

BERNARD CRUMP

Central Birmingham Health Authority,

Birmingham B15 2TZ

General Practitioner,

Tamworth,

Staffordshire B79 7JN

ROGER HAWKES

Unit General Manager (Community and Mental Health),

South East Staffordshire Health Authority,

Burton on Trent DE14 2ED

1 Bevan G, Maynard A, Holland W, Mays N. Reforming UK health care to improve health: the case for research and experiment. York: Centre for Health Economics, University of York, 1989.

2 Drummond M, Maynard A. Efficiency in the NHS: lessons from abroad. Health Policy 1988;9:59-

3 Mechanic D. Consumer choice among health insurance options. Health Affairs 1989;8:138-48.

4 Vladeck B, Goodwin E, Myers L, Sinisi M. Consumers and hospital use: the HCFA "death list." Health Affairs 1988;7:122-5.

Hillman AL. Financial incentives for physicians in HMOs: is there a conflict of interest? N Engl f Med 1987;317:1743-8.

6 Hillman AL, Pauly MV, Kertein JJ. How do financial incentives affect physicians' clinical decisions and the financial performance of health maintenance organisations? N Engl f Med 1989;321:86-

7 Judge K. Monitoring and evaluating Working for Patients. BMF 1989;299:1385-7.

\section{Children with head injuries}

\section{Every district needs a paediatrician to oversee services for them}

Young people are characterised by inexperience, impulsivity, curiosity, bravado, and high levels of physical activity, all of which make them especially vulnerable to accidents. 'Accident prevention programmes are more likely to succeed in changing the environment than the nature of childhood. All children hit their heads hard at some time or other, and one in 15 will have had a head injury that "caused parents serious worry." Children are at risk at all ages, ${ }^{3}$ but boys are injured twice as often as girls. ${ }^{4}$ Fortunately, youth also conveys some protection: children under the age of 10 are many times more likely to survive a given head injury than are the elderly. ${ }^{5}$ Fewer than $5 \%$ die at the site of the accident, and if they reach hospital alive more than $95 \%$ survive. $^{6}$

What long term problems do these survivors have? In the 1970 s neurologists believed that "plasticity" (the ability of the brain to adapt and to recuperate ${ }^{7}$ ) protected the child against the sequelae observed in adults, and that this explained the occasional "miraculous" recovery of a toddler who fell on to his or her head from the window of a tower block and the virtual absence in children of the postconcussion syndrome. ${ }^{8}$ The intelligence quotient after head injury is usually normal, ${ }^{9-12}$ and few children have the sort of detailed neuropsychological assessment that can show specific brain damage. Full neurological examination of a 2 year old can be very difficult, and children do not always present their symptoms in a conventional way. All these factors have combined to make doctors seriously underestimate the extent of the residual problems. Those studies that have looked specifically at children have shown that $20 \%$ of the survivors of severe injury have motor sequelae, and $10 \%$ have severe learning difficulties persisting beyond nine months. ${ }^{13}$ They have difficulties with short term memory, concentration, and the processing of new learning ${ }^{1+17}$; language disorders ${ }^{18-21}$; visuospatial problems ${ }^{22}$; changes in personality ${ }^{23}$; and behavioural or emotional disorders. ${ }^{25}$ Although improvement may continue for at least five years, the most rapid recovery takes place in the first few months. ${ }^{26}$

Last year the Paediatric Neurology Association drew attention to the lack of consistency in the long term management of these children. ${ }^{27}$ Parents who have witnessed the intensive input of skills and technology into the lifesaving process may become frustrated and embittered by the almost complete absence of effective rehabilitation. All too often within a few weeks of injury a child develops severe secondary damage from contractures, abnormal motor patterns, and behavioural disturbances - all of which are preventable. Such a child will end up in a special school, but most who are less severely injured return to mainstream schooling (often "put back a year") with little acknowledgment of their specific learning disability.

This situation could easily be improved. Every child with head injuries, wherever admitted, should be under the care of a paediatrician; a paediatric rehabilitation team should be concerned in the management of severely injured children and their families from the time of admission ${ }^{28}$; and the few children (one every couple of months in an average district) who need intensive inpatient rehabilitation need to be included in the bed allocation. Removing a child to a remote specialist centre is rarely indicated and may perpetuate the delay in obtaining services. Regions might find it more 